\title{
Comparative split-mouth study of the anesthetic efficacy of $4 \%$ articaine versus $0.5 \%$ bupivacaine in impacted mandibular third molar extraction
}

\author{
Hilario Pellicer-Chover ${ }^{1}$, Juan Cervera-Ballester ${ }^{1}$, José María Sanchis-Bielsa ${ }^{2}$, María A. Peñarrocha-Diago ${ }^{3}$, \\ Miguel Peñarrocha-Diago ${ }^{4}$, Berta García-Mira ${ }^{3}$
}

\footnotetext{
${ }^{1}$ Student of the Master's Degree in Surgery and Implant Dentistry, Faculty of Medicine and Dentistry, University of Valencia, Spain.

${ }^{2}$ Associate Lecturer in Oral Surgery, Faculty of Medicine and Dentistry, Adjunct Doctor at Valencia University General Hospital Dental Service, Spain.

${ }^{3}$ Associate Lecturer in Oral Surgery, Faculty of Medicine and Dentistry, University of Valencia, Spain. Lecturer on the Master's Degree in Surgery and Implant Dentistry.

${ }^{4}$ Professor of Oral Surgery and Chairman of the Master's Degree in Surgery and Implant Dentistry, Faculty of Medicine and Dentistry, University of Valencia, Spain.
}

Correspondence:

Clínicas odontológicas

Gascó Oliag 1

46021-Valencia,Spain.

E-mail address: berta.garcia@uv.es
Pellicer-Chover H, Cervera-Ballester J, Sanchis-Bielsa JM, PeñarrochaDiago MA, Peñarrocha-Diago M, García-Mira B. Comparative splitmouth study of the anesthetic efficacy of $4 \%$ articaine versus $0.5 \%$ bupivacaine in impacted mandibular third molar extraction. J Clin Exp Dent. 2013;5(2):e66-71. http://www.medicinaoral.com/odo/volumenes/v5i2/jcedv5i2p66.pdf

Article Number: $50869 \quad$ http://www.medicinaoral.com/odo/indice.htm
(C) Medicina Oral S. L. C.I.F. B 96689336 - eISSN: 1989-5488
eMail: jced@jced.es
Indexed in:
Scopus
DOIß System

\begin{abstract}
Objective: The purpose of this study was to compare the clinical efficacy of articaine at 4\% (epinephrine 1:100,000) with bupivacaine at $0.5 \%$ (epinephrine 1:200,000) for surgical extraction of impacted mandibular third molars. Study Design: This was a randomized, double blind, split-mouth, clinical trial. Thirty-six patients took part and underwent extraction of 72 lower third molars. The variables studied were: anesthetic latency time, intra-operative bleeding, anesthetic quality, hemodynamic changes during the surgical intervention, anesthetic duration in the soft tissues, post-operative analgesia and post-operative pain at 2, 6, 12 and 24 hours using a visual analogue scale, as well as any need for additional rescue medication.

Results: Latency time was 2.0 minutes for articaine and 3.1 minutes for bupivacaine, with statistically significant difference $(p<0.05)$. Bleeding was greater when bupivacaine was used $(p<0.05)$ and anesthetic quality was greater with articaine $(p<0.05)$. The duration of soft tissue anesthesia was longer with bupivacaine $(p<0.05)$. Differences in post-operative analgesia, haemodynamic changes, post-operative pain and the quantity of rescue medication consumed were not statistically significant $(\mathrm{p}>0.05)$.

Conclusions: Articaine showed greater clinical efficacy than bupivacaine, reducing latency time, bleeding, anesthetic duration in the soft tissues and achieving higher anesthetic quality, requiring less reinforcement during surgery than bupivacaine.
\end{abstract}

Key word: Articaine, bupivacaine, anesthetic efficacy, impacted mandibular third molar. 


\section{Introduction}

Impacted lower third molar has a high rate of incidence, third molar extraction being the most frequent extraction performed in the oral cavity (1). It is associated with the appearance of very diverse pathologies such as pericoronitis, caries on the distal face of the second lower molar and on the third molar, myofascial pain, certain types of cyst and odontogenic tumors and dental overcrowding (2). Pain, inflammation and post-operative trismus are the main symptoms following impacted lower third molar surgery $(3,4)$. The pain is more intense between three and five hours after extraction, as the local anesthetic wears off (5), and is generally controlled using analgesics or non-steroidal anti-inflammatory drugs (NSAIDs) taken orally (6).

The application of long-acting local anesthetics has been shown to reduce immediate post-operative pain $(7,8)$. Bupivacaine produces a slow return of sensation that is associated with the gradual onset of post-operative discomfort (3). However, the long duration of anesthesia in the soft tissues is considered an unpleasant sensation for the patient $(6,9,10)$. Its use is justified in surgery of long duration and post-operative periods with foreseeable discomfort $(11,12)$.

Bupivacaine was developed in 1957 by Ekenstam, Egner and Pettersson and its clinical use was first described by Widman in $1964(3,4)$. It was introduced onto the market in 1984 and since then numerous studies have been published comparing it mainly with lidocaine $(3,4$, $6,8,13)$. The results of these trials suggest that bupivacaine was superior due to: similar latency time, four time greater strength, delay to the appearance and intensity of post-operative pain, a reduction to the use of analgesics and the minimal incidence of secondary effects.

There is a wide variety of literature comparing different anesthetics, but only three $(11,14,15)$ have compared bupivacaine with articaine for third molar extraction.
The aim of the present study was to compare the clinical efficacy of articaine at 4\% (epinephrine 1:100,000) with bupivacaine at $0.5 \%$ (epinephrine $1: 200,000$ ) for the surgical extraction of impacted mandibular third molars.

\section{Material and Methods \\ -Sample Selection}

This randomized double blind, split-mouth, clinical trial was performed at the Oral Surgery Unit of a University Clinic. All patients gave their informed consent in writing. The study protocol was approved by the University of Valencia Faculty of Dentistry's ethics committee. Of a total of 220 patients requiring impacted lower third molar extraction between November 2009 and May 2010, the patients selected were all adults requiring bilateral impacted lower third molar extration with similar levels of surgical difficulty according to the Alemany-Martinez et al. scale (16) (Table 1).

Exclusion criteria were: patients presenting systemic diseases, patients in pharmacological treatment (excepting oral contraceptives) and patients allergic to the drugs used in the trial. Having completed a study protocol for each subject, 20 were discarded as they did not meet the criteria. Finally, 36 patients took part (12 men and 24 women), with an average age of $23.1 \pm 6$ years (range 18-37).

\section{-Surgical Procedure}

The articaine and bupivacaine carpules $(1.8 \mathrm{ml})$ were marked as " 1 " or " 2 " by an individual unrelated to the study. The local anesthetic used and the side of the intervention were allotted randomly using a predefined random numbers table and enclosed in envelopes.

At the first intervention, patients received 4\% articaine with 1:100,000 epinephrine (Ultracaine, Inibsa, Barcelona, Spain) or $0.5 \%$ bupivacaine with 1:200,000 epinephrine (Inibsacain Plus ${ }^{\circledR}$, Inibsa, Barcelona, Spain). At the second intervention, the anesthetic not used at the

Table 1.Table showing surgical difficulty in impacted lower third molar extraction as classified by Alemany-Martinez et al. (16).

\begin{tabular}{|c|c|c|c|c|c|}
\hline \multicolumn{2}{|r|}{ Spatial Relation } & \multicolumn{2}{|r|}{ Depth } & \multicolumn{2}{|c|}{ Available Space } \\
\hline 1 & Mesioangular & 1 & Level A & 1 & Class I \\
\hline 2 & Horizontal/transverse & 2 & Level B & 2 & Class II \\
\hline 3 & Vertical & 3 & Level C & 3 & Class III \\
\hline 4 & Distoangular & & & & \\
\hline $\begin{array}{l}\text { Sp: } \\
\text { Thi } \\
\text { De } \\
\text { Lev } \\
\text { mo } \\
\text { the } \\
\text { Avs } \\
\text { Cla } \\
\text { met } \\
\text { the } \\
\text { Le } \\
\text { 3-4 }\end{array}$ & $\begin{array}{l}\text { osition in relation to th } \\
\text { hest part of third molar } \\
\text { n occlusal line and cer } \\
\text { olar cervical line. } \\
\text { ace } \\
\text { space between the dista } \\
\text { hird molar. Class II: Th } \\
\text { al diameter of the third } \\
\text { iculty } \\
\text {; } 5-6, \text { moderate; } 7-10 \text { v }\end{array}$ & $\begin{array}{l}\text { mo } \\
\text { ne } 1 \\
\text { of } \mathrm{t} \\
\text { of } \mathrm{t} \\
\text { etwe } \\
\text { ass } \\
\text { ult. }\end{array}$ & $\begin{array}{l}\text { the plane o } \\
\text { ir. Level C: } \\
\text { ar and the a } \\
\text { arface of th } \\
\text { molar is pa }\end{array}$ & $\begin{array}{l}\text { occ } \\
\text { thir } \\
\text { bul } \\
\text { ind } \\
\text { ins }\end{array}$ & $\begin{array}{l}\text { el } B \text { : Highest part of third } \\
\text { level or below the plane of } \\
\text { r than the mesiodistal dia- } \\
\text { ndibular ramus is less than } \\
\text { mandibular ramus. }\end{array}$ \\
\hline
\end{tabular}


first was applied. In either case, inferior lingual alveolar nerve block was given with $1.8 \mathrm{ml}$ of anesthetic solution using a 27G 35mm long needle (Sofic ${ }^{\circledR}$ XL Monoprotect, France). This was complemented with anesthesia of the buccal nerve, administering $1.8 \mathrm{ml}$ in a second carpule with a $30 \mathrm{G} 25 \mathrm{~mm}$ long needle (Sofic ${ }^{\circledR}$ XL Monoprotect, France). The surgical procedures were performed by dentists with similar levels of surgical experience, in the same surgery and under identical working conditions. A vertical releasing incision was made mesial of the second molar, lifting a mucoperiosteal flap, followed by ostectomy and odontosection. When the third molar had been extracted, suture was performed using $3 / 0$ braided silk (Lorca Marin ${ }^{\circledR}$, Murcia, Spain). As an antibiotic, the patient received $500 \mathrm{mg}$ amoxicillin orally, one tablet every eight hours for one week. Anti-inflammatory treatment consisted of $600 \mathrm{mg}$ ibuprofen taken orally, every eight hours for three days, initiating this treatment when the patient experienced the first instances of pain. As analgesic rescue medication during the post-operative period, one $500 \mathrm{mg}$ paracetamol tablet was administered at the onset of pain.

\section{-Data Collection}

The reasons for extraction were registered, as well as the time required for the surgical intervention (in minutes, timed from incision to suture). The latency time (in minutes from the removal of the needle to the first signs of loss of feeling in the lower lip) was recorded. The surgeon evaluated bleeding classifying it as minimum, normal or abundant at different points during the procedure: after incision, flap elevation, ostectomy, extraction and on completion of suture. Anesthetic quality was classified according to patient discomfort during surgery and the need (or not) to reinforce anesthesia as: no discomfort, slight discomfort but not requiring additional anesthesia, moderate to severe discomfort needing additional anesthetic, in which case the amount of anesthesia required was recorded.

Systolic and diastolic blood pressure, and cardiac rate were monitored using a tensiometer $\left(\mathrm{OMRON}^{\circledR} \mathrm{M} 6\right.$, HEM-7001-E, Paris, France) before beginning surgery, after anesthesia, at the moment of incision, flap elevation, ostectomy, extraction and suture.

Duration of anesthesia in the soft tissues was timed from the first sign of numbness in the lower lip to complete recovery of feeling in the tongue and lower lip. The duration of post-operative analgesia was recorded as the time span from the end of the surgical procedure to ingestion of the first ibuprofen tablet.

Patients noted pain levels at 2, 6, 12 and 24 hours following surgery on a visual analogue scale and whatever rescue medication they needed to take.

-Statistical Analysis

To analyze differences between the type of anesthetic, the student t-test for samples was applied with quantita- tive variables. When the distribution of variables did not fulfill the t-test criteria, the Wilcoxon non-parametric test was used.

The relation between surgical time and post-operative pain was analyzed using the Pearson correlation coefficient. In the case of category variables - bleeding and anesthetic quality - the McNemar-Bowker non-parametric test was applied to determine differences between the two types of anesthetic.

ANOVA was performed on repeated measurements to analyze the effect of the type of anesthesia at each point during the surgical procedure (base-line, anesthesia, incision, flap elevation, ostectomy, extraction and suture) on haemodynamic variables, as well as time $(2,6,12$ and 24 hours) and post-operative pain.

\section{Results}

The most common reason for extraction was pericoronitis antecedents $(47.2 \%)$, followed by prophylactic reasons $(27.8 \%)$, orthodontic requirements $(16.7 \%)$ and second molar affectation ( $8.3 \%$ ).

The average time of surgical procedures was 35.2 minutes on the right side and 38.9 minutes on the left, without statistically significant difference $(\mathrm{t}=-1.797 ; \mathrm{p}=0.081)$. Average latency time for bupivacaine was $3.1 \pm 1.5 \mathrm{mi}-$ nutes compared to $2 \pm 1.4$ minutes for articaine, with statistically significant difference $(Z=-3.810 ; p=0.000)$ (Fig. 1) (Table 2).

There were higher levels of bleeding in surgery performed under anesthesia by bupivacaine, particularly during incision and flap elevation, being abundant in $30.6 \%$ of cases using bupivacaine compared to $2.8 \%$ with articaine $(Z=-3.664 ; p=0.000)$.

Moderate and severe intra-operative discomfort, requiring additional anesthetic occurred in $16.7 \%$ of cases

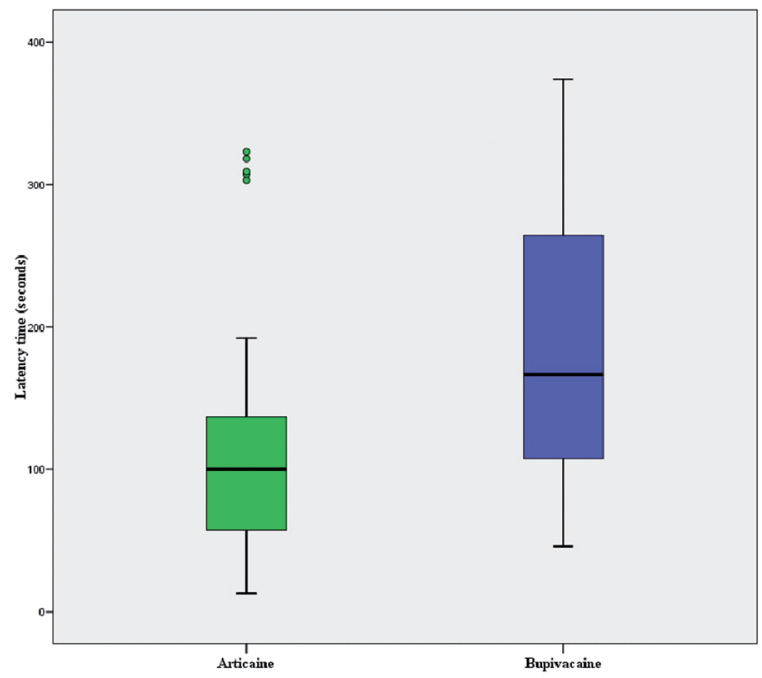

Fig. 1. Average latency time for bupivacaine and articaine. 
Table 2. Objective and subjective parameters recorded in patients following surgical extraction of lower third molars under local anesthetic by articaine or bupivacaine. Mean averages \pm standard deviation.

\begin{tabular}{|c|c|c|c|}
\hline & & Articaine & Bupivacaine \\
\hline \multicolumn{2}{|c|}{ Latency Time (minutes)* } & $2 \pm 1.4$ & $3.1 \pm 1.5$ \\
\hline \multirow{3}{*}{ Haemodynamics } & Systolic Blood Pressure (mmHg) & 124.7 & 124.1 \\
\hline & Diastolic Blood Pressure (mmHg) & 72.6 & 74.3 \\
\hline & Cardiac Rate (ppm) & 81.5 & 80.7 \\
\hline \multirow{4}{*}{ Post-Operative Pain } & 2 hours & $4.2 \pm 0.4$ & $3.5 \pm 0.4$ \\
\hline & 6 hours & $5.7 \pm 0.3$ & $4.7 \pm 0.4$ \\
\hline & 12 hours & $5.3 \pm 0.3$ & $5.1 \pm 0.4$ \\
\hline & 24 hours & $5.2 \pm 0.3$ & $4.3 \pm 0.4$ \\
\hline \multicolumn{2}{|c|}{ Duration of anesthetic Effects on Soft Tissues (minutes)* } & $250.3 \pm 48.3$ & $316.5 \pm 30.1$ \\
\hline \multicolumn{2}{|c|}{ Duration of Post-Operative Analgesia (minutes) } & $203.2 \pm 20.5$ & $215.8 \pm 15.4$ \\
\hline \multicolumn{2}{|c|}{ Rescue Medication Consumption } & $42.8 \%$ & $52.7 \%$ \\
\hline * Statistically significal & $(\mathrm{p}<0.05)$ & & \\
\hline
\end{tabular}

treated with articaine compared to $44.4 \%$ of patients who received bupivacaine $(\mathrm{Z}=-3.220 ; \mathrm{p}=0.001)$. Larger quantities of bupivacaine were needed, with an average of $1.6 \mathrm{ml}$ per extraction, compared to $0.7 \mathrm{ml}$ of articaine; this difference was statistically significant $(\mathrm{t}=-2.572 ; \mathrm{p}$ $=0.014$ ).

Regarding haemodynamic parameters, the type of anesthetic solution did not influence systolic blood pressure $(\mathrm{F}=0.947 ; \mathrm{p}=0.449)$, dystolic blood pressure $(\mathrm{F}=0.958$; $\mathrm{p}=0.414)$ or cardiac rate $(\mathrm{F}=1.006 ; \mathrm{p}=0.409)$ during surgery (Fig. 2 and Table 2).

The duration of anesthetic effect in soft tissues was 250.3 \pm 48.3 minutes with articaine and $316.5 \pm 30.1$ minutes with bupivacaine, with statistically significant difference $(t=-3.239 ; p=0.002)$. The duration of post-operative analgesia was $203.2 \pm 20.5$ minutes with articaine and $215.8 \pm 15.4$ minutes with bupivacaine, without significant difference $(\mathrm{t}=-0.920 ; \mathrm{p}=0.363)$ (Table 2$)$.

Post-operative pain peaked at the six-hour point with articaine and at twelve hours after surgery with bupivacaine, with statistically significant difference $(p=0.004)$ (Fig. 3). The average pain levels for articaine and bupivacaine were 5.1 and 4.4 respectively, without significant difference $(\mathrm{p}=0.072)$ (Table 2). The number of patients needing rescue analgesics was similar between the two groups (articaine $\mathrm{n}=15$, bupivacaine $\mathrm{n}=19$ ) and no significant difference was found for this parameter (Table 2) $(\mathrm{p}=0.836)$.
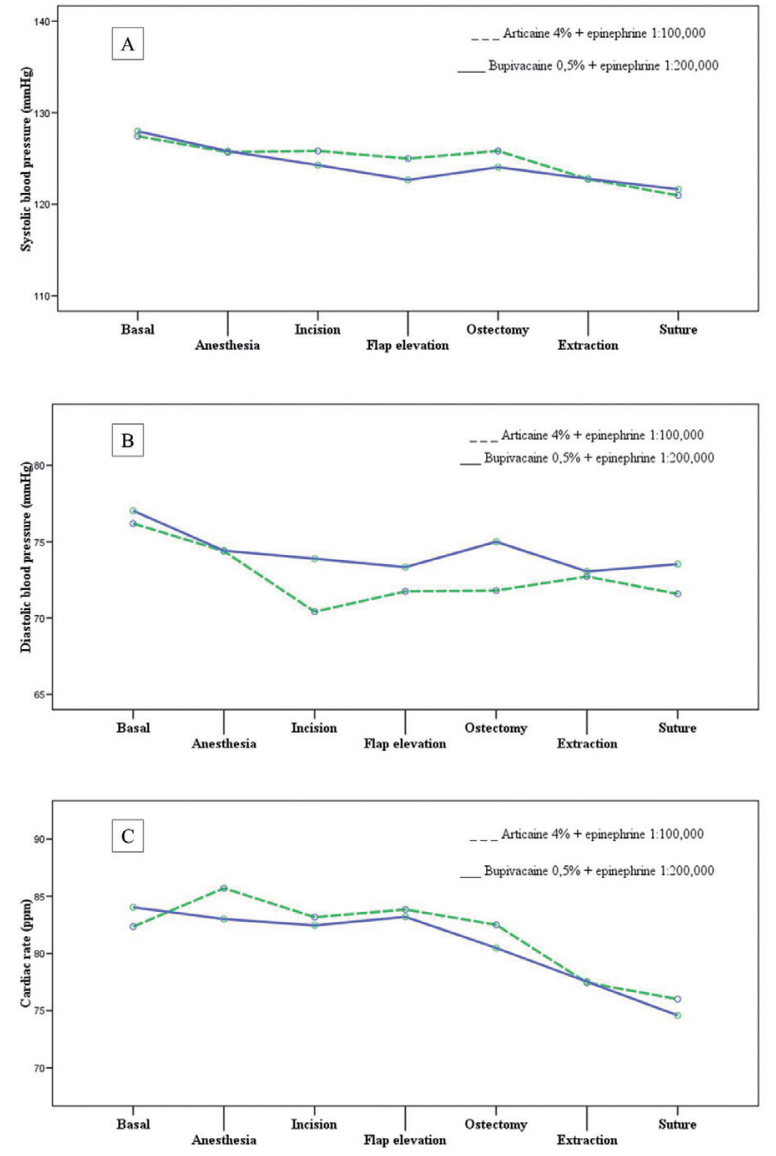

Fig. 2. Influence of type of anesthetic solution on systolic blood pressure, dystolic blood pressure or cardiac rate 


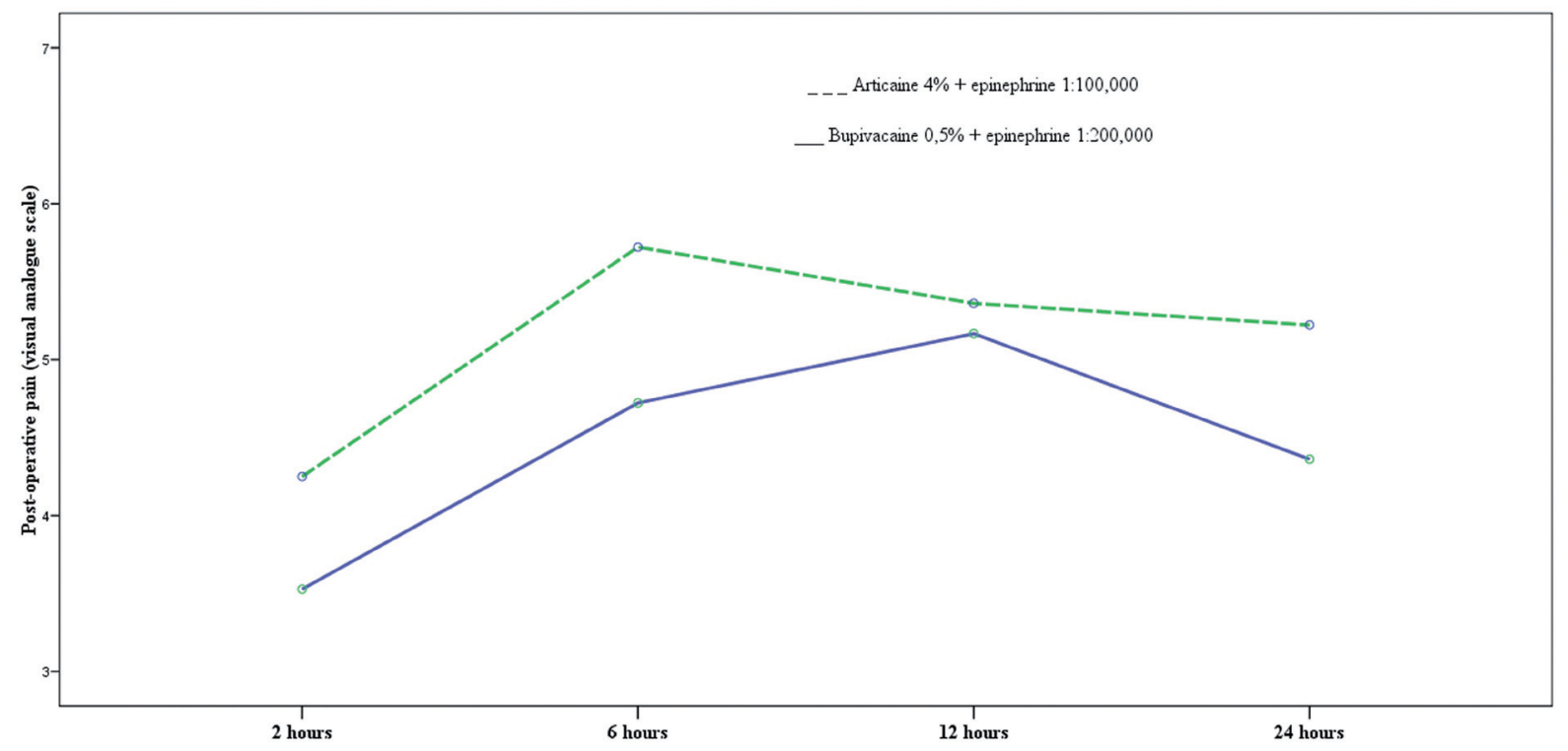

Fig. 3. Evolution of post-operative pain with articaine and bupivacaine.

\section{Discussion}

The present study calculated a mean latency time of two minutes for articaine, results similar to those obtained by Malamed et al. (17), and Sierra Rebolledo et al. (18). For bupivacaine, latency time was 3.1 minutes, coinciding with results published by Gregorio et al. (11) and Trullenque-Eriksson et al. (14). In other studies (15, 1921), latency time for bupivacaine varies between 1.9 and 2.6 minutes, lower values than found in the present study. The difference in latency time between articaine and bupivacaine could be explained by the faster activation of drugs with low $\mathrm{pKa}$, articaine having lower $\mathrm{pKa}$ (7.8) than bupivacaine (8.1).

More bleeding was observed in interventions performed under anesthesia with bupivacaine, a finding that agrees with Buckley et al. (22) and Moore et al. (23), although it should be noted that these authors evaluated hemorrhaging associated with periodontal surgery. However, the results disagree with those obtained by Gregorio et al. (11) and Trullenque-Eriksson y cols. (14) who obtained minimal bleeding during surgery using articaine and bupivacaine, both with epinephrine at 1:200,000. The results of the present study could be interpreted as the effects of a higher concentration of epinephrine in the articaine and the greater vasodilatory capacity of bupivacaine.

In spite of the initial administration of equal volumes of both local anesthetics $(3.6 \mathrm{ml})$, in $22 \%$ of the surgical procedures with bupivacaine the patient complained of discomfort and an additional volume was needed (1.6ml). Only $8 \%$ of cases in which articaine was used required an additional infiltration of the anesthetic solu- tion $(0.7 \mathrm{ml})$. These results coincide with findings obtained by Gregorio et al. (11), whereby $14 \%$ of cases using bupivacaine needed additional anesthetic, compared to $2 \%$ of cases using articaine. However, Trullenque-Eriksson et al. (14) and Sancho-Puchades et al. (15) did not find statistically significant differences in the need for additional anesthetic.

The anesthetic used did not significantly influence blood pressure or heart rate during the different stages of surgery. Bupivacaine was associated with higher diastolic blood pressure than articaine and lower systolic blood pressure and heart rate, but without statistically significant differences. These findings coincide with the majority of published studies $(10,24)$, whereby the presence or absence of vasoconstrictor in the anesthetic did not directly influence blood pressure due to the small quantities involved. Fluctuations in cardiovascular function observed during the surgical procedure could be associated with stress (25).

Duration of anesthesia in the soft tissues was longer with bupivacaine compared to articaine, with statistically significant difference; this is similar to the results of other research $(11,14,15)$. However, these other studies used articaine at 4\% with 1:200,000 epinephrine. The longer duration of soft tissue anesthesia when bupivacaine was used can be explained by its greater fixation to proteins and vasodilatory capacity (26).

As other authors have found $(13,27-30)$, bupivacaine reduced post-operative pain more effectively compared to articaine, although this difference did not reach statistical difference. Pain peaked later (after 12 hours) and with less intensity following the interventions performed 
with bupivacaine compared to articaine, for which pain peaked earlier (after 6 hours) and had more intensity on the visual analogue scale.

Post-operative analgesia was greater for bupivacaine, although the difference was not significant. Other authors have obtained similar results $(11,14)$.

In the present study, the difference in rescue analgesic consumption was not significant, a finding born out by other studies $(11,14,15)$.

Overall, articaine was found to provide greater clinical efficacy than bupivacaine, with shorter latency time, less bleeding, shorter duration of soft tissue anesthesia and better anesthetic quality and required less additional anesthetic compared to bupivacaine.

\section{Conflict of Interest}

The authors declare that they have no conflict of interests.

\section{References}

1. Fardi A, Kondylidou-Sidira A, Bachour Z, Parisis N, Tsirlis A. Incidence of impacted and supernumerary teeth-a radiographic study in a North Greek population. Med Oral Patol Oral Cir Bucal. 2011;16:e56-61.

2. Chaparro-AvendaÒo AV, Pérez-Garcl̀a $S$, Valmaseda-CastellÛn E, Berini-AytĖs L, Gay-Escoda C. Morbidity of third molar extraction in patients between 12 and 18 years of age. Med Oral Patol Oral Cir Bucal. 2005;10:422-31.

3. Chapman PJ, Macleod AW. A clinical study of bupivacaine for mandibular anesthesia in oral surgery. Anesth Prog. 1985;32:6972.

4. Rosenquist JB, Nystrom E. Long-acting analgesic or long-acting local anesthetic in controlling immediate postoperative pain after lower third molar surgery. Anesth Prog. 1987;34:6-9.

5. Fisher SE, Frame JW, Rout PG, McEntegart DJ. Factors affecting the onset and severity of pain following the surgical removal of unilateral impacted mandibular third molar teeth. Br Dent J. 1988;164:351-4.

6. Markovi AB, Todorovi L. Postoperative analgesia after lower third molar surgery: contribution of the use of long-acting local anesthetics, low-power laser, and diclofenac. Oral Surg Oral Med Oral Pathol Oral Radiol Endod. 2006;102:e4-8.

7. Trieger N, Gillen GH. Bupivacaine anesthesia and post-operative analgesia in oral surgery. Anesth Prog. 1979;26:20-3.

8. Rosenquist JB, Rosenquist KI, Lee PK. Comparison between lidocaine and bupivacaine as local anesthetics with diflunisal for postoperative pain control after lower third molar surgery. Anesth Prog. 1988;35:1-4.

9. Mellor DJ, Mellor AH, McAteer EM. Local anaesthetic infiltration for surgical exodontia of third molar teeth: a double-blind study comparing bupivacal̀na infiltration with i.v. ketorolac. Br J Anaesth. $1998 ; 81: 511-4$

10. Fernandez C, Reader A, Beck M, Nusstein J. A prospective, randomized, double-blind comparison of bupivacaine and lidocaine for inferior alveolar nerve blocks. J Endod. 2005;31:499-503.

11. Gregorio LV, Giglio FP, Sakai VT, Modena KC, Colombini BL, Calvo AM, et al. A comparison of the clinical anesthetic efficacy of $4 \%$ articaine and $0.5 \%$ bupivacaine (both with 1:200,000 epinephrine) for lower third molar removal. Oral Surg Oral Med Oral Pathol Oral Radiol Endod. 2008;106:19-28.

12. Volpato MC, Ranali J, Ramacciato JC, de Oliveira PC, Ambrosano GM, Groppo FC. Anesthetic efficacy of bupivacaine solutions in inferior alveolar nerve block. Anesth Prog. 2005;52:132-5.

13. Bouloux GF, Punnia-Moorthy A. Bupivacaine versus lidocaine for third molar surgery: a double-blind, randomized, crossover study. J Oral Maxillofac Surg. 1999;57:510-4; discussion 515.

14. Trullenque-Eriksson A, Guisado-Moya B. Comparative study of two local anesthetics in the surgical extraction of mandibular third molars: bupivacaine and articaine. Med Oral Patol Oral Cir Bucal. 2011;16: e390-6.

15. Sancho-Puchades M, VÌlchez-PÈrez MA, Valmaseda-CastellÛn $\mathrm{E}$, Paredes-Garcl̀a J, Berini-AytÈs L, Gay-Escoda C. Bupivacaine $0.5 \%$ versus articaine $4 \%$ for the removal of lower third molars. A crossover randomized controlled trial. Med Oral Patol Oral Cir Bucal. 2012;17:e462-8.

16. Alemany-Martİnez A, Valmaseda-CastellÛn E, Berini-AytÈs L, Gay-Escoda C. Hemodynamic changes during the surgical removal of lower third molars. J Oral Maxillofac Surg. 2008;66:453-61.

17. Malamed SF, Gagnon S, Leblanc D. Articaine hydrochloride: a study of the safety of a new amide local anesthetic. J Am Dent Assoc. 2001;132:177-85.

18. Sierra Rebolledo A, Delgado Molina E, Berini Aytìs L, Gay Escoda C. Comparative study of the anesthetic efficacy of $4 \%$ articaine versus $2 \%$ lidocaine in inferior alveolar nerve block during surgical extraction of impacted lower third molars. Med Oral Patol Oral Cir Bucal. 2007;12:E139-44.

19. Laskin JL, Wallace WR, DeLeo B. Use of bupivacaine hydrochloride in oral surgery-a clinical study. J Oral Surg. 1977;35:25-9.

20. Moore PA, Dunsky JL. Bupivacaine anesthesia--a clinical trial for endodontic therapy. Oral Surg Oral Med Oral Pathol. 1983;55:176-9.

21. Dunsky JL, Moore PA. Long-acting local anesthetics: a comparison of bupivacaine and etidocaine in endodontics. J Endod. 1984; 10:457-60

22. Buckley JA, Ciancio SG, McMullen JA. Efficacy of epinephrine concentration in local anesthesia during periodontal surgery. J Periodontol. 1984;55:653-7.

23. Moore PA, Doll B, Delie RA, Hersh EV, Korostoff J, Johnson S, et al. Hemostatic and anesthetic efficacy of $4 \%$ articaine $\mathrm{HCl}$ with $1: 200,000$ epinephrine and $4 \%$ articaine $\mathrm{HCl}$ with $1: 100,000$ epinephrine when administered intraorally for periodontal surgery. $\mathrm{J}$ Periodontol. 2007;78:247-53.

24. Santos CF, Modena KC, Giglio FP, Sakai VT, Calvo AM, Colombini BL, et al. Epinephrine concentration $(1: 100,000$ or $1: 200,000)$ does not affect the clinical efficacy of $4 \%$ articalna for lower third molar removal: a double-blind, randomized, crossover study. J Oral Maxillofac Surg. 2007;65:2445-52.

25. Montebugnoli L, Servidio D, Miaton RA, Prati C. Heart rate variability: a sensitive parameter for detecting abnormal cardiocirculatory changes during a stressful dental procedure. J Am Dent Assoc. 2004;135:1718-23.

26. Danielsson K, Evers H, Nordenram A. Long-acting local anesthetics in oral surgery: an experimental evaluation of bupivacalna and etidocaine for oral infiltration anesthesia. Anesth Prog. 1985;32:65-8.

27. Feldmann G, Nordenram A. Marcaine in oral surgery. A clinical comparative study with carbocaine. Acta Anaesthesiol Scand Suppl.1966;23:409-13.

28. Nespeca JA. Clinical trials with bupivacaine in oral surgery. Oral Surg Oral Med Oral Pathol. 1976;42:301-7.

29. Chapnick P, Baker G, Munroe CO. Bupivacaine anaesthesia in oral surgery. J Can Dent Assoc. 1980;46:441-3.

30. Chapman PJ. A controlled comparison of effectiveness of bupivacaine for post-operative pain control. Aust Dent J. 1988;33:28890 . 